University of South Florida

DIGITAL COMMONS

Digital Commons @ University of

@ UNIVERSITY OF SOUTH FLORIDA

South Florida

School of Geosciences Faculty and Staff

Publications

School of Geosciences

$12-1988$

\title{
Variation in Sulfur Dioxide Emissions Related to Earth Tides, Halemaumau Crater, Kilauea Volcano, Hawaii
}

Charles B. Connor

Dartmouth College, cbconnor@usf.edu

Richard E. Stoiber

Dartmouth College

Lawrence L. Malinconico Jr.

Dartmouth College

Follow this and additional works at: https://digitalcommons.usf.edu/geo_facpub

Part of the Earth Sciences Commons

\section{Scholar Commons Citation}

Connor, Charles B.; Stoiber, Richard E.; and Malinconico, Lawrence L. Jr., "Variation in Sulfur Dioxide Emissions Related to Earth Tides, Halemaumau Crater, Kilauea Volcano, Hawaii" (1988). School of Geosciences Faculty and Staff Publications. 1650.

https://digitalcommons.usf.edu/geo_facpub/1650

This Article is brought to you for free and open access by the School of Geosciences at Digital Commons @ University of South Florida. It has been accepted for inclusion in School of Geosciences Faculty and Staff Publications by an authorized administrator of Digital Commons @ University of South Florida. For more information, please contact digitalcommons@usf.edu. 


\title{
Variation in Sulfur Dioxide Emissions Related to Earth Tides, Halemaumau Crater, Kilauea Volcano, Hawaii
}

\author{
Charles B. CONNOR, ${ }^{1}$ Richard E. STOIBer, AND LAWrence L. Malinconico, JR. ${ }^{2}$ \\ Deparment of Earth Sciences, Dartmouth College, Hanover, New Hampshire
}

\begin{abstract}
Variation in $\mathrm{SO}_{2}$ emissions from Halemaumau crater, Kilauea volcano, Hawaii is analyzed using a set of techniques known as exploratory data analysis. $\mathrm{SO}_{2}$ flux was monitored using a correlation spectrometer. A total of 302 measurements were made on 73 days over a 90 -day period. The mean flux was $171 \mathrm{t} / \mathrm{d}$ with a standard deviation of $52 \mathrm{t} / \mathrm{d}$. A significant increase in flux occurs during increased seismic activity beneath the caldera. $\mathrm{SO}_{2}$ flux prior to the this change varies in a systematic way and may be related to variation in the tidal modulation envelope.
\end{abstract}

\section{INTRODUCTION}

Daily $\mathrm{SO}_{2}$ flux is considered to reflect the state of activity of a volcano and increases by orders of magnitude during and often prior to eruptions [Menyailov, 1975; Malinconico, 1979; Stoiber et al., 1980]. Most studies of daily variation of $\mathrm{SO}_{2}$ flux describe a constant flux with random departures from the mean. Changes in activity are denoted by nonrandom departures [Greenland $e t$ al., 1985; Stoiber et al., 1986]. In this study, $\mathrm{SO}_{2}$ flux was measured several times daily at Halemaumau crater, Kilauea volcano, Hawaii, over a period of several months (Figure 1). Exploratory data analysis techniques [Tukey, 1977; Cleveland and Kleiner, 1975; Kleiner and Graedel, 1980] reveal systernatic variations in $\mathrm{SO}_{2}$ flux that are smaller than changes attributable to changes in the level of volcanic activity. The departures from the mean flux can be correlated with oscillation in stress induced by Earth tides. Other observed changes in $\mathrm{SO}_{2}$ flux during the time interval of the study can be related to concomitant changes in seismic activity.

Many authors have noted a correlation between volcanic eruptions and Earth tides [Eggers and Decker, 1969; Hamilton, 1973; Johnston and Mauk, 1972; Mauk and Johnston, 1973; Golombek and Carr, 1978; Mauk, 1979] and volcanic earthquakes and tides [Mauk and Kienle, 1973; McNutt and Beavan, 1981]. Stoiber et al. [1986] related nonrandom variation in $\mathrm{SO}_{2}$ flux from Masaya volcano, Nicaragua, to gas bursts triggered by tides. Sugisaki [1981] noted a correlation between tides and variation in $\mathrm{He} / \mathrm{Ar}$ in gas bubbles along active faults. A correlation between Earth tides and the frequency of geyser eruptions has also been identified [Rhinehart, 1976]. At Kilauea volcano, Brown [1925] discovered that the level of Halemaumau lava lake, present earlier this century, rose and fell in response to lunar tides. Dzurisin [1980] found that eruptions of Kilauea tend to occur at fortnightly tidal maxima. Dzurisin et al. [1984] found that tilt measurements at the volcano had a pronounced oscillation corresponding to fortnightly tidal period over several months in 1980 . Therefore we hypothesized that Earth tides may cause variation in $\mathrm{SO}_{2}$ flux from Kilauea.

\footnotetext{
${ }^{1}$ Now at Department of Geology, Florida Intemational University, Miami.

${ }^{2}$ Now at Department of Geology, Southem Illinois University, Carbondale.
}

Copyright 1988 by the American Geophysical Union.

Paper number 88JB03300.

0148-0227/88/88JB0330\$05.00
METHODS AND RESULTS

Remote correlation spectrometry is commonly used to estimate $\mathrm{SO}_{2}$ flux from volcanoes [Stoiber and Jepson, 1973; Malinconico, 1979; Haulet et al., 1977; Stoiber et al., 1983; Williams et al., 1986]. $\mathrm{SO}_{2}$ measurements were made at Halemaumau crater on 73 days between June 10 and September 12, 1979, using a Barringer COSPEC IV following the methods of Malinconico [1979]. A total of 302 measurements were made during this time. Data were collected between 0900 and 1500 local time; usually four measurements of flux were made per day.

The mean flux between June 10 and September 12 was $171 \mathrm{t} / \mathrm{d}$ with a standard deviation of $52 \mathrm{t} / \mathrm{d}$. This flux is typical for Kilauea [Stoiber and Malone, 1975; Stoiber et al., 1979; Greenland et al., 1985; Gerlach and Greaber, 1985], although it is relatively small for an actively degassing volcano [Stoiber and Jepson, 1973; Williams et al., 1986; Stoiber et al., 1987]. According to the model of Gerlach and Greaber [1985] for the degassing of Kilauea, this $\mathrm{SO}_{2}$ is a constituent of "chamber" gas, representing volatile loss as a parental magma equilibrates with reservoir magma between 1 and 6 $\mathrm{km}$ beneath the caldera, as opposed to degassing associated with enuptive activity.

Because variance in $\mathrm{SO}_{2}$ flux is greater on days having a higher mean flux, the $\ln \left(\mathrm{SO}_{2}\right)$ was calculated; a scatter plot of $\ln \left(\mathrm{SO}_{2}\right)$ over time is given in Figure 2. Moving statistics [Cleveland and Kleiner, 1975] werd adopted to search for structure in this data set. This method is used because it provides a robust/resistant method of assessing data in which noise is high compared to the signal and the density of sampling points varies with time [Kliener and Graedel, 1980]. Both of these features are present in the $\mathrm{SO}_{2}$ flux data

Three moving statistics are used to enhance the scatter plot. These are the midmean [Tukey, 1977] and the lower and upper semimidmeans [Cleveland and Kleiner, 1975]. For a given flux value $X_{r}$ the midmean is the average flux for the $r$ samples collected closest in time to $X_{r}$ and which fall between the upper and lower quartiles of the probability distribution for these $r$ flux values. The lower and upper semimidmeans are means calculated using flux values less than and greater than the median flux of $r$ samples, respectively. As with all moving average techniques, the degree of smoothing depends on $r$, the number of adjacent points used to calculate the moving statistics. There is no set criteria for selecting $r$, and in practice, several values of $r$ are used [Cleveland and Kleiner, 1975]. Structure in the data is enhanced using these moving statistics because, for example, the midmean resists variation produced by extreme values and rapid flucutations.

We chose values of $r$ ranging from 4 to 40 sample points. Rapid fluctuations in $\mathrm{SO}_{2}$ flux dominate the time series when little 


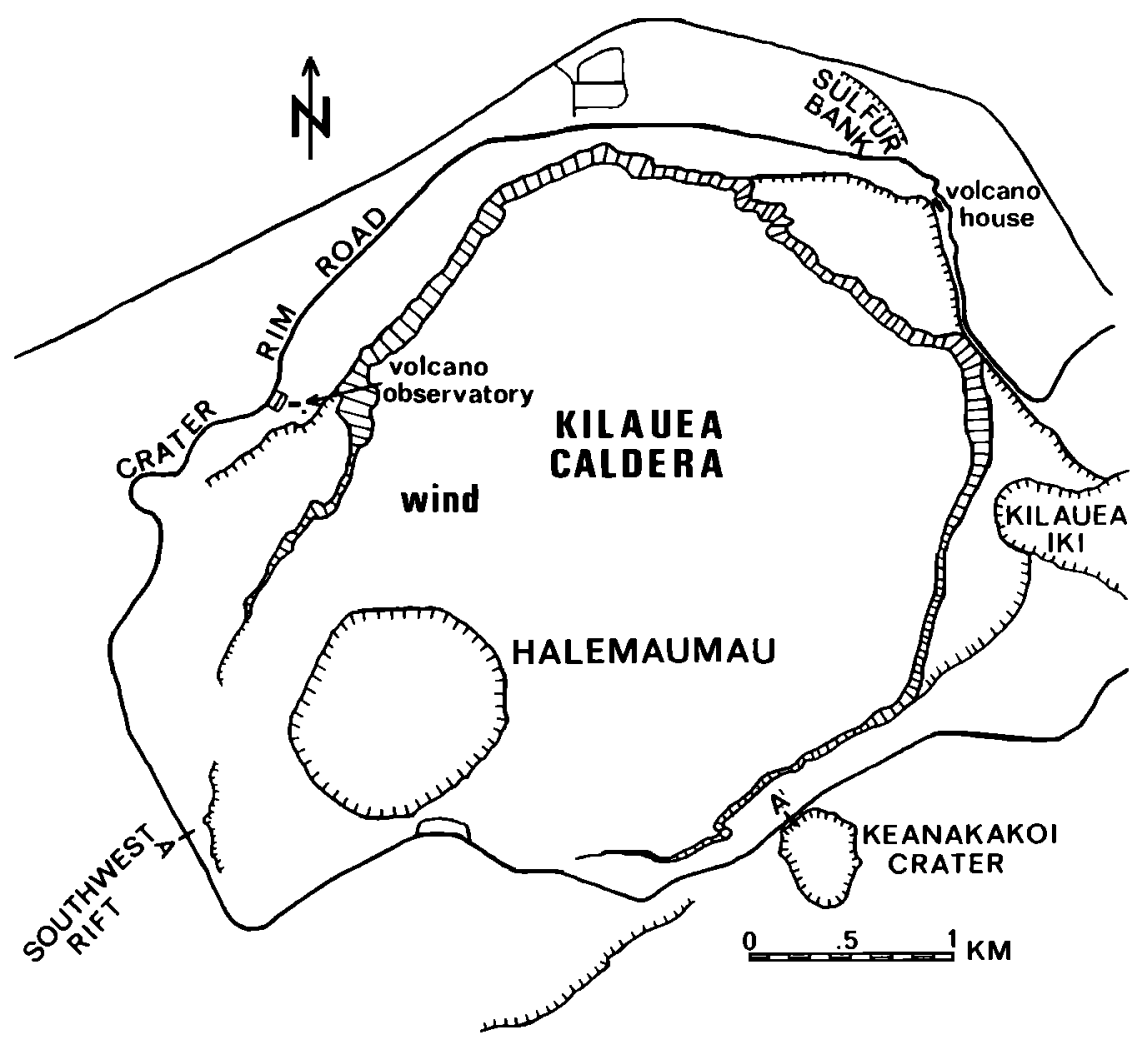

Fig. 1. Kilmea calder and associzted structures. $\mathrm{SO}_{2}$ flux from within Halemaumau crater and the immediately surrounding areas was measured. Fault scarps and crater rims are indicated by hachured lines; wind direction is indicated by the shaded arrow. Measurements were collected along the crater rim roed between $A$ and $A$ :

smoothing is done (e.g. $r=12$ ). Variation is characterized by spikes, and little or no long-wavelength variation can be discerned. The spikes disappear when a slightly larger smoothing factor is used ( $r=18$ ) (Figure 2). At this level of smoothing, several longer-wavelength variations are clear, such as a broad peak in flux around day 30, with two smaller peaks on either side, and a rapid increase in flux near day 52 . Following day 52, the midmean $\ln \left(\mathrm{SO}_{2}\right)$ is generally larger than it was earlier in the time series. The upper semimidmean also increases during this period. The lower semimidmean is not consistently larger, indicating that after day 52 ,

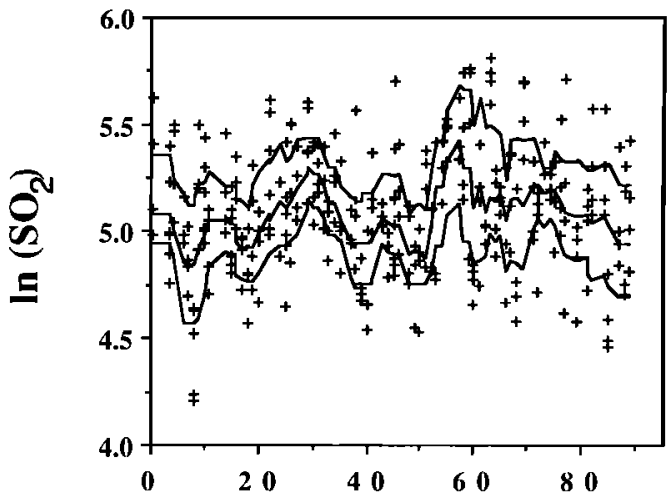

Time (days)

Fig. 2. Scatter plot of $\ln \left(\mathrm{SO}_{2}\right)$ over time with the moving statistics ( $\left.r=18\right)$ cuperimposed: top curve, upper semimidmean; middle curve, midmean; bottom curve, lower cemimidmean. Time is in days since June 10, 1979.
$\mathrm{SO}_{2}$ flux is generally greater but occasional readings are low. Long-wavelength variation persists even at large smoothing factors (e.g. $r=36$ ); the broad peak around day 30 and the increase in $\mathrm{SO}_{2}$ flux initiated by the rapid increase in flux around day 52 are still evident.

Temporal variation in the midmean $\ln \left(\mathrm{SO}_{2}\right)$ flux, calculated vertical tidal acceleration, and the frequency of earthquakes beneath Kilauea caldera are compared in Figure 3. Although Kilauea did not erupt during the sampling period, there was a dramatic increase in seismic activity in early August (day 52), which has been interpreted to be related to the intrusion of a dike at depth (R.W. Decker, personal communication, 1987). As noted above, there is an increase in $\mathrm{SO}_{2}$ flux during this same period. The flux prior to day 52 was less than after day 52 , inclusive, with $>99 \%$ confidence.

High $\mathrm{SO}_{2}$ values, however, do not always occur on the same day as earthquake swarms. This results in a relatively low correlation between $\mathrm{SO}_{2}$ flux and earthquakes; $r=0.21$ for short-period earthquakes and $r=0.26$ for long-period earthquakes. These correlations do not improve by lagging the midmean $\ln \left(\mathrm{SO}_{2}\right)$ with respect to earthquakes or vice versa. This change is seismicity effectively subdivides the data set into flux values collected prior to the onset of seismic swarms and measurements collected after the onset of seismic swarms on day 52.

The $\ln \left(\mathrm{SO}_{2}\right)$ and the midmean of $\ln \left(\mathrm{SO}_{2}\right)$ flux were each compared with several aspects of Earth tides. These include the magnitude of the total vector and the vertical component of tidal acceleration at the time of measurement and the range of these measures over the previous 6,12 , and 24 hours. The derivatives of the horizontal components of tides across the caldera at azimuths 


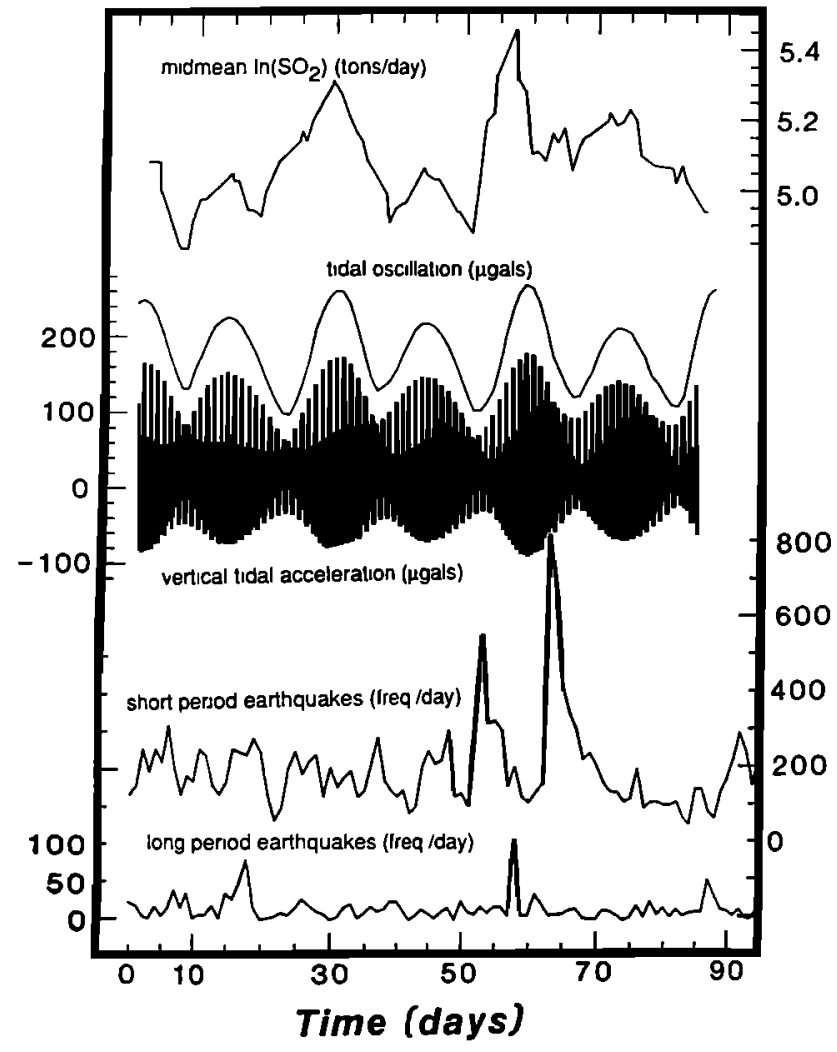

Fig. 3. Comparison of the midmean $\ln \left(\mathrm{SO}_{2}\right)$ for $r=18$ with tidal oscillation, calculated by differencing the langest and amallest upward tidal acceleration during the tidal day, the total upward acceleration, calculated at hourly intervals, and short- and long-period earthquakes. Time is in days since June 10, 1979.

ranging from east-west to north-south at $2^{\circ}$ intervals, and the ranges of these were also compared with $\mathrm{SO}_{2}$ flux. These calculations were made for the entire time series, the time series prior to day 52 , and the series from day 52 onward. All tidal calculations were made following the methods of Longman [1959] and Pollack [1973].

The range of tidal acceleration was determined by differencing the maximum and minimum acceleration occurring within a given interval. The tidal oscillation is modulated at approximately 14-day wavelengths but is not produced by the $M_{f}$ and $M_{m}$ tidal waves, which are fortnightly and monthly lunar waves, respectively [Melchoir, 1978]. Generally, the tidal modulation envelope is out of phase with $M_{f}$ and $M_{m}$, and $M_{f}$ and $M_{m}$ have very small amplitudes relative to the tidal modulation envelope. The modulation is produced by the addition of the $M_{2}$ and $S_{2}$ semidiumal waves, and the semidiurnal lunar elliptic, $N_{2}$. Since $M_{2}, S_{2}$, and $N_{2}$ have slightly different frequencies, a long wavelength modulation develops. Although the modulation is approximately fortnightly, it is produced by semidiumal variations in tidal acceleration.

McNutt and Beavan [1981] successfully related the frequency of earthquakes beneath Pavlof volcano to the orientation of the horizontal component of tides. In the present study it is found that the correlation between flux and the horizontal component of tides was low $(r=0.36)$ and did not improve with changes in orientation.

The coefficients for some of the correlations between $\mathrm{SO}_{2}$ flux and vertical tides are given in Table 1 . The largest correlation coefficients, $r \approx 0.60$, are found by comparing the midmean $\ln \left(\mathrm{SO}_{2}\right)$ flux prior to the onset of earthquake activity with the scalar and with the vertical component of tidal oscillation over a 24-hour period. Lagging the midmean $\ln \left(\mathrm{SO}_{2}\right)$ with respect to tidal oscillation rapidly reduces this correlation, until the curves are again in phase.

\section{DISCUSSION AND CONCLUSIONS}

Intermittency, turbulence, and puffiness in the plume [Venkatram, 1979; Hanna, 1984; Sykes, 1984] and variable wind speed and direction [Stoiber et al., 1980] leads to random variations in estimates of $\mathrm{SO}_{2}$ flux. Processes acting on the magma itself, such as the development of slugs of gas in the conduit [Imai, 1983], may also produce rapid fluctuations in $\mathrm{SO}_{2}$ flux. Nonetheless, pattern in

TABLE1. Correlation Coefficients Between $\mathrm{SO}_{2}$ Flux and Calculated Tides

\begin{tabular}{|c|c|c|c|c|c|c|}
\hline & $\boldsymbol{N}$ & T1 & T2 & $\mathrm{T3}$ & T4 & T5 \\
\hline \multicolumn{7}{|l|}{ Total dato set } \\
\hline $\ln \left(\mathrm{SO}_{2}\right)$ & 302 & 0.06 & 0.13 & 0.20 & 0.16 & 0.18 \\
\hline Midmean $\ln \left(\mathrm{SO}_{2}\right)$ & & 0.17 & 0.26 & 0.38 & 0.32 & 0.31 \\
\hline \multicolumn{7}{|c|}{ Data collected before day 52} \\
\hline $\ln \left(\mathrm{SO}_{2}\right)$ & 183 & -0.01 & 0.09 & 0.08 & 0.22 & 0.24 \\
\hline Midmeen $\ln \left(\mathrm{SO}_{2}\right)$ & & 0.23 & 0.45 & 0.41 & 0.60 & 0.61 \\
\hline \multicolumn{7}{|c|}{ Dete collected after doy 52} \\
\hline $\ln \left(\mathrm{SO}_{2}\right)$ & 119 & 0.17 & 0.22 & 0.24 & 0.13 & 0.21 \\
\hline Midmean $\ln \left(\mathrm{SO}_{2}\right)$ & & 0.25 & 0.15 & 0.34 & 0.18 & 0.28 \\
\hline
\end{tabular}

Linear correlntion coefficients for $h\left(\mathrm{SO}_{2}\right)$ flux and the vertical tidal acceleration at the time of measurement (T1), range of tidal acceleration over the previous 6 hours (T2), 12 hours (T3), 24 hours (T4), and the range of magnitude of the total vector of acceleration over the previous 24 hours (T5). $N$ is the number of samples. The midmean is calculated for a smoothing factor of 18 samples. 
$\mathrm{SO}_{2}$ flux from Halemaumau crater does emerge through the use of exploratory data analysis techiques (Figure 3).

Brown [1925] (also see Shimozuru [1987]) observed that the lava lake level of Halemaumau crater, molten earlier this century, varied with the lunar tide. Furthermore, variations as would be expected, increased as the width of the tidal modulation envelope increased. When the width of the tidal modulation envelope is small, the magma experiences little displacement over time, and any degassing which takes place is presumably related to other processes, such as the equilibration of parent and reservoir magmas or crystallization. When the modulation envelope is wide, daily tidal oscillation is high and the rate of change in tidal stress is maximum. Under these circumstances the conduit magma has been observed to be displaced by as much as $30-60 \mathrm{~cm}$ over a 24-hour period [Shimozuru, 1987] and changes in the rate of vesiculation probably occur [Huppert et al., 1982; Rymer and Brown, 1987]. This, in turn, should increase the rate of degassing.

Changes in the midmean $\ln \left(\mathrm{SO}_{2}\right)$ of the order of $40 \mathrm{t} / \mathrm{d}$ were observed near days 15 and 45 , and $70 \mathrm{t} / \mathrm{d}$ on and around day 30 (Figure 3). The correlation between the midmean $\ln \left(\mathrm{SO}_{2}\right)$ flux $(r=$ 18 ) and the daily tidal oscillation is not statistically significant, but a relationship is suggested by 1 ) the persistence of variation in the midmean $\ln \left(\mathrm{SO}_{2}\right)$ to large smoothing factors, 2$)$ the tendency for $\mathrm{SO}_{2}$ flux to increase when the tidal modulation envelope is large, and 3 ) the decrease in this correlation when the midmean $\ln \left(\mathrm{SO}_{2}\right)$ is lagged with respect to tidal oscillation. Degassing increased significantly during the second half of the observaton period, associated with an increase in seismicity. These observations suggest that monitoring $\mathrm{SO}_{2}$ degassing can, under some circumstances, provide valuable information concerning the relative movement of magma.

Acknowlegments. The support of Stanley Williams, Tom Casadevall of the Hawaiian Volcano Observatory, Chuck Drake, and Robert Decker is greatly appreciated. We appreciate the comments of John Ferguson, who suggested the use of exploratory data analysis techniques, and Fred Mauk. This work was supported by NASA grant NSG5014.

\section{REFERENCES}

Brown, E.W., Tidal oscillations in Halemaumau, the lava pit of Kilauea, Am. J. Sci., 9, 95-112, 1925.

Cleveland, W.S., and B. Kleiner, Enhancing scatter plots with moving statistics, Technometrics, 17, 447-454, 1975.

Dzurisin, D., Influence of fortnightly Earth tides at Kilauea volcano, Hawaii, Geophys. Res. Lett., 7, 925-928, 1980.

Dzurisin, D., R.Y. Koyangi, and T.T. English, Magma supply and storage at Kilauea volcano, Hawaii, 1956-1983, J. Volcanol. Geotherm. Res., 21, 177-206, 1984.

Eggers, A.A., and R.W. Decker, Frequency of historic volcanic emptions, Eos Trans. AGU, 50, 343, 1969.

Gerlach, T.M., and E.J. Greaber, Volatile budget of Kilauea volcano, Nature, 313, 273-277, 1985.

Golombek, M.P., and M.J. Carr, Tidal triggering of seismic and volcanic phenomena during the 1879-1880 enuption of Isles Quemadas volcano in El Salvador, Central America, J. Volcanol. Geotherm. Res., 3, 299-307, 1978.

Greenland, L.P., Gas composition of the Janaury, 1983 enuption of Kilauea volcano, Hawaii, Geochim. Cosmochim. Acta, 48, 193-195, 1984.

Greenland, L.P., W.I. Rose, and J.B. Stokes, An estimate of gas emissions and magmatic gas content from Kilauea volcano, Geochim. Cosmochim. Acta, 49, 125-129, 1985.
Hamilton, W.L., Tidal cycles and volcanic eruptions: Fortnightly to 19 yearly periods, J. Geophys. Res., 78, 3363-3375, 1973.

Hanna, S.R., The exponential probability density function and concentration fluctuations in smoke plumes, Boundary Layer Meteord., 29, 361-375, 1984.

Haulet, R., P. Zettwoog, and J.C. Sabroux, Sulfur dioxide discharge from Mt. Ena, Nature, 268, 715-717, 1977.

Huppert, H.E., R.SJ. Sparks, and J.S. Tumer, Effects of volatiles on mixing in calc-alkline magma systems, Nature, 297, 554-557, 1982.

Imai, H., A mechanism of successive eruption as inferred from seismic data associated with the 1973 eruptive stage of Asama volcano, in Arc Volcanism: Physics and Tectonics editied by D. Shimozuru and I. Yokoyama, pp. 63-82, Terra Scientific, Tokyo, 1983.

Johnston, M.J., and F.J. Mauk, Earth tides and the triggering of eruptions from Mt. Stromboli, Italy, Nature, 239, 266-267, 1972.

Kleiner, B., and T.E. Graedel, Exploratory data analysis in the geophysical sciences, Rev. Geophys., 18, 699-717, 1980.

Longman, I.M., Fomulas for computing the tidal acceration due to the Moon and the Sun, J. Geophys. Res., 64, 2351-2355, 1959.

Malinconico, L.L., Jr., Fluctuations in $\mathrm{SO}_{2}$ emission during recent enuptions of Etna, Nature, 278, 43-45, 1979.

Mauk, F.J., The triggering of activity at Soufrier De St. Vincent, April 1979, by solid earth tides, Eos Trans. AGU, 60, 833, 1979.

Mauk, F.J., and M.J.S. Johnston, On the triggering of volcanic eruptions by Earth tides, J. Geophys. Res., 78, 3356-3362, 1973.

Mauk, F.J., and J. Kienle, Microearhquakes of St. Augustine volcano, Alaska, triggered by Earth tides, Science, 182, 386-389, 1973.

McNutt, S.R., and R.J. Beavan, Volcanic earthquakes at Palvof volcano correlated with solid Earth tide, Natwre, 294, 615-618, 1981.

Melchoir, P., Tides of the Planet Earth, 607 pp., William Clowes, London, 1978.

Menyailov, L., Prediction of enuptions using changes in the compositions of volcanic gases, Bull. Volcanol., 26, 367-378, 1975.

Mysen, B.O., The solubility of $\mathrm{H}_{2} \mathrm{O}$ and $\mathrm{CO}_{2}$ under predicted magma genesis conditions and some petrological and geophysical implications, Rev. Geophys., 15, 351-361, 1977.

Pollack, H.N., Longman tidal formulas: Resolution of horizontal components, J. Geophys. Res., 78, 2598-2600, 1973.

Rhinehart, J.S., Influence of tidal strain on geophysical phenomena, In Proceedings of the Seventh Symposium on Earth Tides edited by G. Szadeczky-Kardoss, pp 181-186, Stuttgart, Federal Republic of Germany, 1976.

Rymer, H., and G.C. Brown, Causes of microgravity change at Poás volcano, Costa Rica: An active but non-erupting system, Bull. Volcanol., 49, 389-398, 1987.

Shimozuru, D., Tidal effects on Hawaiian volcanism, inVolcanism in Hawaii, vol. 2, edited by R.W. Decker, T.L. Wright, and P.H. Stauffer, U.S. Geol. Surv. Prof. Pap., 1350, 1337-1344, 1987.

Sparks, R.S.J., The dynamics of bubble growth and formation in magmas: A review and analysis, J. Volcanol. Geotherm. Res., 3, 1-37, 1978.

Stoiber, R.E., and A. Jepson, Sulfur dioxide contributions to the atmosphere by volcanoes, Science, 182, 577-578, 1973.

Stoiber, R. E., and G. Malone, $\mathrm{SO}_{2}$ emission at the crater of Kilauea, at Mauna Ula, and at the Sulfur Banks, Hawaii, Eos Trans. AGU, 56, 461, 1975.

Stoiber, R.E., L.L. Malinconico, and T.J. Casadevall, $\mathrm{SO}_{2}$ monitoring by remore sensing at Kilmea volcsno, Hawaii, in Abstract Volume, Hawaii, Symposium on Intraplate Volcanism and Submarine Volcanism, p. 174, Hilo, Hawaii, , 1979.

Stoiber, R.E., S.N. Williams, and L.L. Malinconico, Mount St.Helens, Washington, 1980 volcanic eruption: Magmatic gas component during the first 16 days, Science, 208, 1258-1259, 1980. 
Stoiber, R.E., L.L. Malinconico, and S.N. Williams, Use of the correlation spectrometer at volcanoes, in Forecasting Volcanic Events, edited by H.Tazieff and J.C. Sabroux, pp. 425-444, Elsevier, New York, 1983.

Stoiber, R.E., S.N. Williams, and B. Huebert, Sulfur and halogen gases at Masaya caldera compex, Nicaragua: Total flux and variations with time, J. Geophys. Res., 91, 12,215-12,231, 1986.

Stoiber, R.E., S.N. Williams, and B. Huebert, Annual contribution of sulfur dioxide to the atmosphere by volcanoes, J. Volcanol. Geotherm. Res., 33, 1-9, 1988.

Sugisaki, R., Deep-seated gas emission induced by Earth tide: $\mathbf{A}$ basic observation for geochemical earthquake prediction, Science, 212, 12641266, 1981.

Sykes, R.I., The variance in time averaged samples from an intermittent plume, Atmos. Environ., 18, 121-123, 1984.

Tukey, J.W., Exploratory Data Analysis, Addison-Wesley, Reading, Mass., 1977.

Venkatram, A., The expected deviation of observed concentrations from predicted ensemble means, Atmos. Environ., 13, 1547-1549, 1979.
Williams, S.N., R.E. Stoiber, N. Garcia P., A. Londono C., J.B. Gemmell, D.R. Lowe, and C.B. Connor, Eruption of Nevado Del Ruiz volcano, Colombin, on 13 November 1985: Gas flux and fluid geochemistry, Science, 233, 964-967, 1986.

C. B. Connor, Deptartment of Geology, Florida Intemational University, Miami, FL 33199.

L. L. Melinconico, Jr., Department of Geology, Southern Illinois Univensity, Carbondale, IL 62901.

R. E. Stoiber, Department of Earth Sciences, Darmouth College, Hanover, NH 03755.

(Recieved January 11, 1988; revised July 18, 1988;

accepted July 19, 1988.) 